\title{
Radium in drinking water and risk of bone cancer in Ontario youths: a second study and combined analysis
}

\author{
Murray M Finkelstein, Nancy Kreiger
}

\begin{abstract}
Objectives-Radium induces bone sarcomas at high doses, but there is controversy about risk at low doses. A previous study in Ontario found an association between the presence of radium in birthplace water supplies and an increased risk of death from bone cancer in young people. An investigation was performed to test the findings of the previous study with an independent group of subjects for whom complete information on radium exposure would be obtained.
\end{abstract}

Methods-A population based casecontrol study ( 238 cases; 432 controls) was conducted with incident cases of bone sarcoma identified from the Ontario cancer registry. Residential histories were collected by questionnaire and water samples were obtained and analysed for radium content.

Results-There was an association between risk of osteosarcoma and birthplace exposures (odds ratios (ORs) and $90 \%$ confidence intervals (90\% CIs) 1.77 $(1 \cdot 03-3 \cdot 00)$ but not with lifetime measures of exposure. When lifetime exposure was dichotomised, the OR was 1.31 (0.762.24) for osteosarcoma. There was no trend with increasing exposure. Bootstrap resampling was used to simulate lifetime doses in a pooled analysis of 1293 subjects from the two Ontario studies. The ORs were $1.38(1.08-1 \cdot 73)$ for all sarcomas, and $1.44(1.01-1.87)$ for osteosarcoma. Geometric mean doses in bone were about 26 mRad.

Ontario Ministry of Labour

M M Finkelstein

Department of

Preventive Medicine

and Biostatistics,

University of Toronto

M M Finkelstein

N Kreiger

Department of Family and Community Medicine, University of Toronto

M M Finkelstein

Ontario Cancer Treatment and Research Foundation N Kreiger

Correspondence to: Dr Murray Finkelstein Ontario Ministry of Labour, 400 University Avenue, 7 th Floor, Toronto, Ontario, Canada M7A 1T7.

Accepted for publication 15 December 1995
Conclusions-An association was found between the presence of radium in birthplace water supplies and increased risk of bone sarcoma in two studies. Increased risk was present for lifetime measures of exposure, but the association was not significant, and there was no dose-response trend. Our findings are compatible with the absence of risk at low doses, but they might also reflect inadequate statistical power to measure a true risk at environmental exposure levels. If the increased risk at environmental doses is causal, risk of bone sarcoma is effectively linearly related to dose over five orders of magnitude.

(Occup Environ Med 1996;53:305-311)

Keywords: radium; bone sarcoma; drinking water; case-control study
With the possible exception of the association between lung cancer and exposure to radon, ${ }^{1}$ increased risk of cancer among populations exposed to increased levels of environmental radioactivity has not been found. The radioactive element radium is a decay product of heavier elements in soil and rock. Radium is found in food, and in communities where wells are used, drinking water can be an important source for ingestion. Bone is the principal repository for retained radium because of the chemical similarity between radium and calcium. Information on the health effects of radium comes from extensive studies in humans and experimental animals. The most important effects are the induction of bone and sinus cancers. ${ }^{2}$ The United States Public Health Service (US PHS) ${ }^{3}$ studied bone cancer mortalities in communities in Iowa and Illinois in which water supplies contained at least $3 \mathrm{pCi} / 1(110 \mathrm{mBq} / \mathrm{l})^{\star}$ of radium. There were 25 deaths from bone cancer in people under the age of 30 , in exposed towns compared with 15 deaths in unexposed towns (one tailed $P=0.08$ ).

In 1981 , a survey of radioactivity of groundwaters in southwestern Ontario discovered that radium concentrations in several towns exceeded the Canadian target concentration of $100 \mathrm{mBq} / 1$. An epidemiological study (the mortality study) found an association between measured concentrations of radium in drinking water supplies of the birthplace identified from birth certificates and an increased risk of death from bone cancer in young people across the province. ${ }^{4}$ This report presents the results of a second investigation in Ontario (the registry study) the goal of which was to test the findings of the mortality study with an independent group of subjects for whom complete information on radium exposure would be obtained.

\section{Materials and methods}

STUDY SUBJECTS

This was a population based case-control study. Cases were people of under 26 born in Ontario, identified from the Ontario cancer registry with a diagnosis of primary bone sarcoma (ICDM 918-926) during 1964-88.

$\star$ The Becquerel $(\mathrm{Bq})$ is a measure of the activity of a radioactive sample. It is equal to 1 disintegration per second. A milliBecquerel thus corresponds to one disintegration per 1000 seconds. An older system of units measured activity in picoCuries $(\mathrm{pCi})$ and $1 \mathrm{pCi}=37$ $\mathrm{mBq}$. 
Table 1 Subjects in the Ontario cancer registry study

\begin{tabular}{lcc}
\hline & $\begin{array}{l}\text { Cases } \\
n(\%)\end{array}$ & $\begin{array}{l}\text { Controls } \\
n(\%)\end{array}$ \\
\hline $\begin{array}{l}\text { Subjects enrolled in study } \\
\text { Sex: }\end{array} \quad 238$ & 432 \\
$\quad$ Male & $135(60)$ & $250(62)$ \\
$\quad$ Female & $91(40)$ & $149(38)$ \\
Age distribution (y): & $64(28)$ & $114(29)$ \\
$<12$ & $110(49)$ & $175(44)$ \\
$12-18$ & $52(23)$ & $110(28)$ \\
$19-25$ & & $169(39)$ \\
Measurements of radium in water: & $32(13)$ & 399 \\
$\quad$ Address information only from birth certificate & 226 & 245 \\
$\quad$ Birthplace water sample & 196 & \\
Complete lifetime residence samples & &
\end{tabular}

Subjects in the previous study were excluded. ${ }^{4}$ Two control subjects with cancer, matched on sex, age, and year of diagnosis, were selected from the Ontario cancer registry for each case. The registry required approval from the attending physician before contacting the subjects or their families. After approval from the physician, each subject's mother was sent a residential history questionnaire.

Potential cases (491), people with a bone cancer code in the cancer registry, were identified first. Two hundred and seven (207) subjects were ineligible because they did not have a primary bone cancer on further examination of registry data or because they were outside the eligible age range. Five were excluded because the physician refused approval to contact the family, and 23 were abandoned because a physician could not be located to grant approval for contact. This left 256 bone cancer cases eligible for inclusion in the study. Due to an administrative error $18(7 \%)$ were omitted from the study because questionnaire replies had not been received for these subjects on the last date at which information could be provided to the person sampling water. Data from birth certificates should have been given to the sampler so that partial analysis could be undertaken, but this was not done.

Control subjects were selected on an ongoing basis as the eligibility of cases was verified. Forty two were abandoned because the physician refused approval to contact the family, 139 because a physician could not be located to grant approval for contact, and 143 were ineligible because they did not have a malignancy on further examination of the registry data or because they were outside the eligible age range. Replacements were drawn for these subjects as necessary. This was an iterative process, and we ran out of time to make the final replacements. The final sample was 483 controls and 256 cases, a matching ratio of $1 \cdot 89: 1$, slightly less than the $2: 1$ ratio planned for.

Table 1 shows that the number of controls actually included in the study was only 432 . Because of an administrative error, 51 (11\%) were omitted. On the last date at which information could be provided to the person sampling water, questionnaire replies had not been received for 13 subjects. Birthplace data should have been taken from the birth certificate for partial analysis, but this was not done. Also, birth certificate data should have been used for 22 non-respondents and 16 subjects whose parents returned, but did not complete, the questionnaires. Birth certificate data had been used for these two categories of case subjects.

Table 1 gives information about the distributions of sex and age in the study population. Table 2 gives the distribution of pathological types of bone sarcoma and the distribution of cancer diagnoses among the control subjects for whom a water sample could be collected.

WATER SAMPLING

Table 1 gives details of the samples obtained. Due to non-response and incomplete replies, full residence histories were not obtained for all subjects. Address information was available only from the birth certificate for $13 \%$ of cases and $39 \%$ of controls (a major treatment centre refused us access to the records of 163 controls). Water samples were collected at residences identified on the questionnaires or the birth certificates. Individual samples were collected from residences supplied by wells, and representative samples were taken from municipal supplies. We attempted to bypass water softeners installed since the birth of the subject. Water was collected in acidified jugs, the samples were filtered, and the radon emanation method was used to measure ${ }^{226} \mathrm{Ra}$ concentrations. ${ }^{5}$ Quality control procedures included the collection of duplicate samples, submission of distilled water blanks, and measurement of samples spiked with a known concentrations of radium. Based upon radiochemical considerations, ${ }^{6}$ samples containing less than $7 \mathrm{mBq} / 1$ of ${ }^{226} \mathrm{Ra}$ were categorised as the reference level. Subjects ingesting water containing $7 \mathrm{mBq} / 1$ or more of ${ }^{226} \mathrm{Ra}$ were categorised as exposed.

METABOLIC MODEL FOR RADIUM STORAGE AND CUMULATIVE ACTIVITY IN BONE

We wished to study risk with respect to a measure of dose to bone as well as the concentration of radium in the water supply. We thus used the model for radium uptake and retention developed by Leggett and colleagues ${ }^{7}$ to compute the activity of radium in bone relative to the residential exposure history. According to this model, for a person born at time $T$, the amount, $Q(t)$, of radium in the skeleton at age $t$ is described by the equation:

$$
\mathrm{dQ} / \mathrm{dt}=\mathrm{B}(\mathrm{t}) \mathrm{A}(\mathrm{t}) \mathrm{D}(\mathrm{T}+\mathrm{t})-\mathrm{L}(\mathrm{t}) \mathrm{Q}(\mathrm{t})
$$

where: $B(t)$ is the fraction of ingested radium taken up at age $t ; A(t)$ is the amount of calcium ingested per year at age $t ; D(T+t)$ is the concentration of radium per $\mathrm{g}$ calcium in the diet at time $(T+t) ; L(t)$ is the biological removal constant at age $t$. If there is an initial amount, $Q(0)$, in the skeletal compartment at birth, then the radium content of bone (the number of disintegrations in bone at age $t$ ) is:

$$
\begin{gathered}
Q(t)=\left(\exp \left(-\int_{0}^{t} L(s) d s\right)\right) \times(Q(0)+ \\
\int_{0}^{t} B(w) A(w) D(T+w) \times \\
\left.\exp \left(\int_{0}^{w} L(s) d s\right) d w\right)
\end{gathered}
$$


Table 2 Distribution of diagnoses and birthplace exposures from drinking water samples among cases and controls

\begin{tabular}{|c|c|c|}
\hline Diagnosis & $n$ & $\begin{array}{l}\text { Exposed } \\
\text { (birthplace) } \\
n(\%)\end{array}$ \\
\hline $\begin{array}{l}\text { Cases (total): } \\
\text { Osteosarcoma } \\
\text { Ewing's sarcoma } \\
\text { Chondrosarcoma } \\
\text { Others }\end{array}$ & $\begin{array}{r}226 \\
118 \\
72 \\
19 \\
17\end{array}$ & $\begin{array}{l}31(13 \cdot 7) \\
20(16 \cdot 9) \\
9(12 \cdot 5) \\
2(10 \cdot 5) \\
0\end{array}$ \\
\hline $\begin{array}{l}\text { Controls (total): } \\
\text { Oral cavity and pharynx } \\
\text { Digestive }\end{array}$ & $\begin{array}{r}399 \\
12 \\
13\end{array}$ & $\begin{array}{l}41(10 \cdot 2) \\
1(8) \\
3(23) \\
\quad(2 \text { of } 5 \text { colon })\end{array}$ \\
\hline $\begin{array}{l}\text { Cardiorespiratory } \\
\text { Connective and soft tissue } \\
\text { Melanoma } \\
\text { Female genital } \\
\text { Testis } \\
\text { Urinary } \\
\text { Eye }\end{array}$ & $\begin{array}{r}11 \\
18 \\
28 \\
17 \\
33 \\
13 \\
4\end{array}$ & $\begin{array}{l}0 \\
5(28) \\
7(25) \\
1(6) \\
3(9) \\
0 \\
0\end{array}$ \\
\hline $\begin{array}{l}\text { Brain and central } \\
\text { nervous system } \\
\text { Thyroid } \\
\text { Other endocrine } \\
\text { Lymphosarcoma } \\
\text { Hodgkin's disease } \\
\text { Lymphoid leukaemia } \\
\text { Myeloid leukaemia } \\
\text { Poorly specified }\end{array}$ & $\begin{array}{l}82 \\
24 \\
14 \\
20 \\
34 \\
34 \\
11 \\
31\end{array}$ & $\begin{array}{l}8(10) \\
1(4) \\
0 \\
2(10) \\
4(12) \\
4(12) \\
0 \\
2(6)\end{array}$ \\
\hline
\end{tabular}

This equation was evaluated with the age dependent parameters for A, B, and L published by Leggett et al. ${ }^{7}$ We used the water sampling results and an estimate of the age dependent volume of tap water ingested to find $\mathrm{D}(\mathrm{t}) .^{9}$ Exposures in the reference category were assigned a value of $3.5 \mathrm{mBq} / \mathrm{l}$, the midpoint of the reference interval, 0 to $7 \mathrm{mBq} / \mathrm{l}$.

Conversion of the number of disintegrations to dose is complicated, particularly in growing bone with changing bone mass and geometry. The cumulative dose at the age of diagnosis is a function of the number of radium disintegrations in bone from the unborn period to the time of diagnosis. To avoid the uncertainties of conversion from disintegrations to dose, we performed most of the computations using radium disintegrations in bone. The simplest measure was to accumulate disintegrations until two years before the diagnosis of cancer (assuming a two year interval between malignant transformation and diagnosis). As the cumulative number of disintegrations is age dependent, we defined a normalised measure "cumulative activity ratio", the ratio of a subject's cumulative activity to that of a reference subject of the same age whose lifetime exposures were all in the reference category. The cumulative activity ratio for the subjects of this study ranged from 1.0 to 142 .

\section{STATISTICAL METHODS}

Age stratified odds ratios (ORs) and confidence intervals (CIs) were computed with the EGRET computer program. ${ }^{10} \mathrm{We}$ present one tailed $P$ values and $90 \% \mathrm{CI}$ as it is known that radium causes bone cancer. The bootstrap method was used to select random samples, with replacement, from the pooled populations of the registry and mortality studies to compute statistics for the pooled populations. ${ }^{11}$

\section{Results}

ANALYSES OF BIRTHPLACE RESIDENCE

The previous study examined the risk of death from bone sarcoma in relation to birthplace exposures, and we first present results in relation to that measurement. ${ }^{4}$ Table 2 shows the distributions of birthplace exposure to radium among the cases and controls, by diagnosis. Subjects with exposure to water containing radium in concentrations of $7 \mathrm{mBq} / 1$ or more were classified as exposed. Of subjects with osteosarcoma $17 \%$ were exposed at their birthplace, compared with $10 \%$ of control subjects. It is noteworthy that subjects with lymphatic or haematopoietic cancers were no more frequently exposed than other controls, and that none of the 11 with myeloid leukaemia had been exposed. Table 3 shows age adjusted ORs with a dichotomous exposure classification for the presence of radium in the birthplace water supply. The OR estimates for the registry and mortality studies are similar. In a pooled analysis, the ORs for all sarcomas and osteosarcoma were significantly increased. They were also increased for Ewing's sarcoma and chondrosarcoma, but not significantly so. The mean birthplace exposure of exposed subjects was $26 \mathrm{mBq} / 1$ (geometric mean: $15.5 \mathrm{mBq} / \mathrm{l}$ ).

Table 3 also shows exposure-response relations with three birthplace exposure categories. The ORs in the two studies differ in the highest exposure category. This might be attributable to chance variation, as the numbers in this category are very small. In the pooled population there was a significant test for trend with increasing birthplace exposure

Table 3 Analysis of the present study (the registry study) and previous mortality study with the results of birthplace water sampling

\begin{tabular}{|c|c|c|c|c|c|c|c|c|c|}
\hline \multirow[b]{2}{*}{ Exposure } & \multicolumn{3}{|c|}{ All sarcoma } & \multicolumn{2}{|c|}{ Osteosarcoma } & \multicolumn{2}{|c|}{ Ewing's sarcoma } & \multicolumn{2}{|c|}{ Chondrosarcoma } \\
\hline & Cases & Controls & OR $(90 \% C I)$ & Cases & OR $(90 \% C I)$ & Cases & OR $(90 \% C I)$ & Cases & OR $(90 \% C I)$ \\
\hline $\begin{array}{l}\text { Registry study: } \\
\text { Reference level } \\
\text { All exposed } \\
7 \cdot 0-29.9 \mathrm{mBq} / 1 \\
\geqslant 30 \mathrm{mBq} / 1\end{array}$ & $\begin{array}{r}195 \\
31 \\
27 \\
4\end{array}$ & $\begin{array}{r}358 \\
41 \\
34 \\
7\end{array}$ & $\begin{array}{l}1.0 \\
1.37(0.87-2 \cdot 15) \\
1.45(0.89-2.35) \\
0.93(0.24-3.27)\end{array}$ & $\begin{array}{r}98 \\
20 \\
18 \\
2\end{array}$ & $\begin{array}{l}1.0 \\
1.77(1.03-3.00) \\
1.93(1.08-3.38) \\
1.02(0.15-4.49)\end{array}$ & $\begin{array}{r}63 \\
9 \\
7 \\
2\end{array}$ & $\begin{array}{l}1.0 \\
1.26(0.59-2.50) \\
1.18(0.50-2.54) \\
1.65(0.24-7.24)\end{array}$ & $\begin{array}{r}17 \\
2 \\
2 \\
0\end{array}$ & $\begin{array}{l}1 \cdot 0 \\
1 \cdot 03(0 \cdot 2-4) \\
1 \cdot 25(0 \cdot 2-5) \\
0\end{array}$ \\
\hline $\begin{array}{l}\text { Mortality study: } \\
\text { Reference level } \\
\text { All exposed } \\
7 \cdot 0-29 \cdot 9(\mathrm{mBq} / 1 \\
\geqslant 30 \mathrm{mBq} / 1\end{array}$ & $\begin{array}{r}240 \\
43 \\
35 \\
8\end{array}$ & $\begin{array}{r}256 \\
29 \\
26 \\
3\end{array}$ & $\begin{array}{l}1.0 \\
1.59(1 \cdot 01-2 \cdot 51) \\
1.44(0 \cdot 89-2 \cdot 36) \\
2.91(0 \cdot 83-13)\end{array}$ & $\begin{array}{r}125 \\
20 \\
15 \\
5\end{array}$ & $\begin{array}{l}1 \cdot 0 \\
1 \cdot 40(0 \cdot 80-2 \cdot 44) \\
1 \cdot 16(0 \cdot 62-2 \cdot 15) \\
3 \cdot 64(0 \cdot 87-17 \cdot 9)\end{array}$ & $\begin{array}{r}93 \\
15 \\
13 \\
2\end{array}$ & $\begin{array}{l}1 \cdot 0 \\
1.45(0.77-2 \cdot 66) \\
1.42(0.72-2 \cdot 72) \\
1.84(0.22-12)\end{array}$ & $\begin{array}{l}9 \\
3 \\
2 \\
1\end{array}$ & $\begin{array}{l}1 \cdot 0 \\
3 \cdot 5(0 \cdot 7-13) \\
2 \cdot 85(0 \cdot 39-14) \\
11 \cdot 8(0 \cdot 4-156)\end{array}$ \\
\hline $\begin{array}{l}\text { Combined studies: } \\
\text { Reference level } \\
\text { All exposed } \\
7.0-29.9 \mathrm{mBq} / 1 \\
\geqslant 30 \mathrm{mBq} / 1\end{array}$ & $\begin{array}{r}435 \\
74 \\
62 \\
12\end{array}$ & $\begin{array}{r}614 \\
70 \\
60 \\
10\end{array}$ & $\begin{array}{l}1.0 \\
1.48(1.09-2.02) \\
1.45(1.04-2.02) \\
1.70(0.76-3.84)\end{array}$ & $\begin{array}{r}223 \\
40 \\
33 \\
7\end{array}$ & $\begin{array}{l}1 \cdot 0 \\
1.55(1 \cdot 06-2 \cdot 24) \\
1.47(0.98-2 \cdot 20) \\
2 \cdot 02(0.77-5 \cdot 13)\end{array}$ & $\begin{array}{r}156 \\
24 \\
20 \\
4\end{array}$ & $\begin{array}{l}1.0 \\
1.35(0.85-2.09) \\
1.32(0.80-2 \cdot 12) \\
1.65(0.45-4.63)\end{array}$ & $\begin{array}{r}26 \\
5 \\
4 \\
1\end{array}$ & $\begin{array}{l}1 \cdot 0 \\
1 \cdot 82(0.6-5) \\
1 \cdot 72(0 \cdot 53-4 \cdot 6) \\
2 \cdot 66(0 \cdot 12-17)\end{array}$ \\
\hline
\end{tabular}


Table 4 The ORs derived from lifetime radium exposure histories in the registry study and inferred from birthplace exposures in the bootstrap analysis of the pooled populations of the registry and mortality studies (dichotomous exposure classification)

\begin{tabular}{|c|c|c|c|c|c|}
\hline & \multicolumn{2}{|l|}{ Cases } & \multicolumn{2}{|l|}{ Controls } & \multirow[b]{2}{*}{ OR $(90 \% C I)$} \\
\hline & Exposed & Reference level & Exposed & Reference level & \\
\hline $\begin{array}{l}\text { All sarcomas: } \\
\text { Registry study } \\
\text { Simulation study }\end{array}$ & 40 & 156 & 44 & 201 & $\begin{array}{l}1.17(0.76-1.80) \\
1.38(1.08-1.73)\end{array}$ \\
\hline $\begin{array}{l}\text { Osteosarcoma: } \\
\text { Registry study } \\
\text { Simulation study }\end{array}$ & 25 & 78 & 44 & 201 & $\begin{array}{l}1.31(0.76-2.24) \\
1.44(1.01-1.87)\end{array}$ \\
\hline $\begin{array}{l}\text { Ewing's sarcoma: } \\
\text { Registry study } \\
\text { Simulation study }\end{array}$ & 12 & 53 & 44 & 201 & $\begin{array}{l}1.07(0.53-2.07) \\
1.29(0.85-1.81)\end{array}$ \\
\hline $\begin{array}{l}\text { Chondrosarcoma: } \\
\text { Registry study } \\
\text { Simulation study }\end{array}$ & 2 & 14 & 44 & 201 & $\begin{array}{l}0.69(0 \cdot 10-2 \cdot 82) \\
1.72(0.70-3 \cdot 19)\end{array}$ \\
\hline
\end{tabular}

Table 5 Risk of bone sarcoma in relation to the cumulative activity ratio, the ratio of a subject's cumulative lifetime exposure to the cumulative lifetime exposure of a subject without measurable radium exposure

\begin{tabular}{|c|c|c|c|}
\hline Pathology and dose & $\begin{array}{l}\text { Cases } \\
n\end{array}$ & $\begin{array}{l}\text { Controls } \\
n\end{array}$ & OR $(90 \% C I)$ \\
\hline $\begin{array}{l}\text { All sarcomas: } \\
\text { Reference level }\end{array}$ & 156 & 201 & $1 \cdot 0$ \\
\hline $\begin{array}{l}\text { Activity ratio }=1.01 \text { to } 2.99 \text { : } \\
\text { Registry study } \\
\text { Simulation study }\end{array}$ & 22 & 20 & $\begin{array}{l}1.33(0.73-2.43) \\
1.63(1.20-2.16)\end{array}$ \\
\hline $\begin{array}{l}\text { Activity ratio } \geqslant 3 \cdot 0: \\
\text { Registry study } \\
\text { Simulation study }\end{array}$ & 18 & 24 & $\begin{array}{l}0.92(0.50-1.70) \\
1.17(0.79-1.62)\end{array}$ \\
\hline $\begin{array}{l}\text { Osteosarcoma: } \\
\text { Reference level }\end{array}$ & 78 & 201 & $1 \cdot 0$ \\
\hline $\begin{array}{l}\text { Activity ratio }=1.01 \text { to } 2.99 \text { : } \\
\text { Registry study } \\
\text { Simulation study }\end{array}$ & 14 & 20 & $\begin{array}{l}1.57(0.76-3.20) \\
1.67(1.09-2.34)\end{array}$ \\
\hline $\begin{array}{l}\text { Activity ratio } \geqslant 3 \cdot 0: \\
\text { Registry study } \\
\text { Simulation study }\end{array}$ & 11 & 24 & $\begin{array}{l}1.06(0.48-2.44) \\
1.24(0.78-1.82)\end{array}$ \\
\hline $\begin{array}{l}\text { Ewing's sarcoma: } \\
\text { Reference level }\end{array}$ & 53 & 201 & $1 \cdot 0$ \\
\hline $\begin{array}{l}\text { Activity ratio }=1.01 \text { to } 2.99 \text { : } \\
\text { Registry study } \\
\text { Simulation study }\end{array}$ & 6 & 20 & $\begin{array}{l}1.14(0.41-2.91) \\
1.52(0.90-2.30)\end{array}$ \\
\hline $\begin{array}{l}\text { Activity ratio } \geqslant 3 \cdot 0: \\
\text { Registry study } \\
\text { Simulation study }\end{array}$ & 6 & 24 & $\begin{array}{l}0.95(0.35-2.37) \\
1.09(0.58-1.70)\end{array}$ \\
\hline $\begin{array}{l}\text { Chondrosarcoma: } \\
\text { Reference level }\end{array}$ & 14 & 201 & $1 \cdot 0$ \\
\hline $\begin{array}{l}\text { Activity ratio }=1.01 \text { to } 2.99 \text { : } \\
\text { Registry study } \\
\text { Simulation study }\end{array}$ & 2 & 20 & $\begin{array}{l}1.42(0.19-6.96) \\
1.98(0.50-4.45)\end{array}$ \\
\hline $\begin{array}{l}\text { Activity ratio } \geqslant 3 \cdot 0: \\
\text { Registry study } \\
\text { Simulation study }\end{array}$ & 0 & 24 & $\begin{array}{l}0(0 \cdot 00-3 \cdot 02) \\
1 \cdot 54(0 \cdot 43-3 \cdot 14)\end{array}$ \\
\hline
\end{tabular}

for all sarcomas $(P=0.029)$ and for osteosarcoma $(P<0.01)$.

\section{LIFETIME EXPOSURE MEASUREMENTS}

Subjects with lifetime exposure measurements included 245 control subjects and 103 case subjects with osteosarcoma, 65 with Ewing's sarcoma, 16 with chondrosarcoma, and 12 with other bone sarcoma pathologies. Table 4 shows the ORs for a dichotomous lifetime exposure classification, in which subjects with exposure to water containing radium in concentrations of $7 \mathrm{mBq} / 1$ or more at any residence were classified as exposed. The ORs for all sarcomas and osteosarcoma were increased, but not significantly so. The mean and geometric mean cumulative activity ratios among the exposed subjects were $7 \cdot 2$ and $3 \cdot 6$, respectively.

A cut off point at activity ratio $=3.0$ divided the exposed subjects into two groups of 42 subjects each. Table 5 shows that the ORs were increased in the middle dose category, and then declined. The mean and geometric mean activity ratios were 2.0 and 1.9 among subjects in the 1.01 to 2.99 category and 12.4 and 7.1 in the 3.0 or more category.

Moolgavkar and colleagues have developed biologically based models of cancer that take account of the numbers of cells at risk of malignant transformation. ${ }^{12} \mathrm{We}$ used this two stage clonal expansion model to compute a dose adjusted for the population of stem cells at risk and the dynamics of initiated cells. Adjustment had little effect on the relative size of the doses, and the results were similar to those with unweighted accumulation.

For subjects from the cancer registry, the results from lifetime exposure histories were thus qualitatively similar to those obtained from the analysis of birthplace exposures. There was a modest increase in the OR of the middle dose category and a decline in the highest dose category.

\section{Discussion}

Bone sarcoma is the fourth most common malignant neoplasm in children and young adults. ${ }^{13}$ Osteogenic sarcoma and Ewing's sarcoma account for about $80 \%$ of these tumours. Among the rarer histologies about $10 \%$ are chondrosarcoma and another $3 \%$ are fibrosarcoma. With the exception of ionising radiation, the causes of childhood bone cancer are essentially unknown. Some of the factors that have been considered include hormonal control, viruses, chemical exposures, and familial factors. Tucker and colleagues reported a relative risk of $4 \cdot 7$ for developing bone cancer after exposure to alkylating agents as treatment for a previous childhood cancer. ${ }^{14}$

The first case of bone sarcoma associated with radium exposure was reported in 1929 in a woman who had worked as a luminescent dial painter. These workers rotated the tips of brushes contaminated with paint containing radium between their lips to create a fine point for painting. Subsequent studies of cohorts of luminescent dial painters found extraordinarily high risks of bone sarcomas. ${ }^{15}$ The induced tumours were primarily osteosarcoma and fibrosarcoma, with a smaller proportion of 
chondrosarcoma. No cases of bone sarcoma were found among dial painters with a dose less than 1000 Rad. In the medical setting, bone tumours were reported among patients injected with ${ }^{224} \mathrm{Ra}$ for therapeutic purposes between 1946 and 1951. Some 53 of 898 people injected with ${ }^{224} \mathrm{Ra}$ have been diagnosed with bone sarcomas. ${ }^{16}$ There were 19 sarcomas among adults, primarily osteosarcoma with one fibrosarcoma; among children, there were 32 osteosarcomas and four chondrosarcomas. The absence of Ewing's sarcoma, which is almost as common as osteosarcoma in childhood, is notable. More recently, Tucker et al studied the development of bone sarcomas among children after treatment with radiotherapy and chemotherapy for a first cancer. Of the 64 bone sarcomas 44 were osteosarcomas, 11 were chondrosarcomas, three were Ewing's sarcomas (the first cases described after exposure to radiation), and two were fibrosarcomas. The radiation sensitive sarcomas in children thus seem to be osteosarcoma and chondrosarcoma. Fibrosarcoma and Ewing's sarcoma have appeared, but much less frequently. Osteosarcoma occurs with high frequency in subjects who carry a mutant gene at the retinoblastoma locus. Experimental evidence supports the theory that radiation destroys the remaining normal copy of this gene. ${ }^{17}$

Radium exposure is known to induce bone sarcomas at high doses, but there is controversy about risk at low doses. Raabe et al proposed the existence of a practical threshold for sarcomas induced by ${ }^{226} \mathrm{Ra}$ at a dose of 80 Rad. ${ }^{18} \mathrm{His}$ model assumed that the time from start of irradiation to appearance of sarcomas doubled for every 10-fold decrease in dose rate, suggesting that at low doses the time to appearance of the tumour is longer than a lifespan. Mays, however, suggested that a true threshold might be as small as the energy required to disrupt a single molecule of DNA. ${ }^{19}$ A previous investigation in Ontario found an association between low level exposure to radium in birthplace drinking water and an increased risk of death from bone sar-

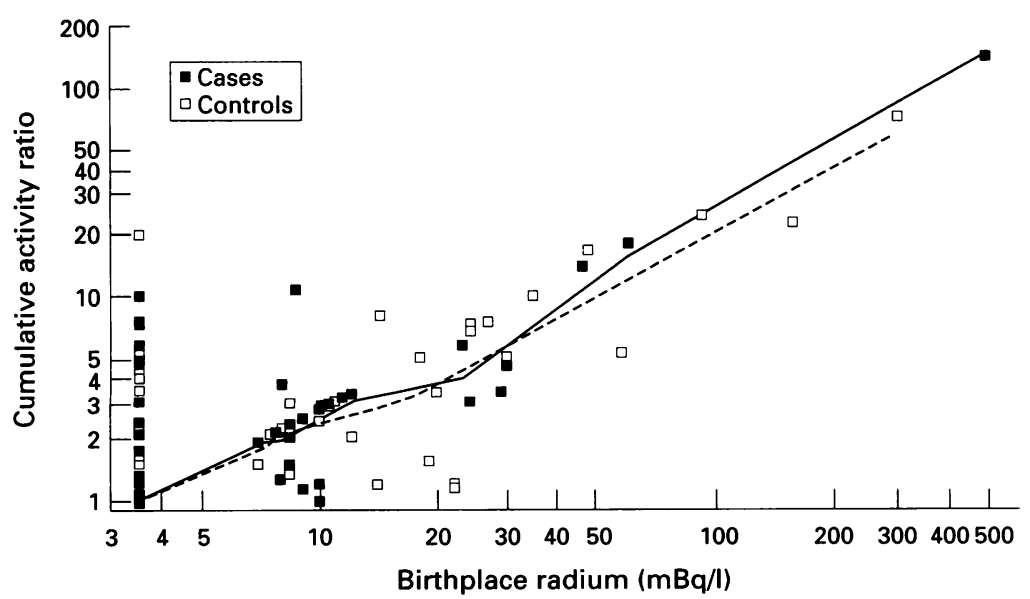

Figure 1 The correlation between birthplace exposure and cumulative activity ratio for case and control subjects. The vertical column near the origin subjects who were unexposed at their birthplace, but exposed in subsequent houses. The lines are loess regression lines fitted to the data. coma. ${ }^{4}$ The study we report here supports the earlier findings in relation to birthplace exposure, but the results of the analyses with lifetime exposure histories are not significant, and do not show a trend with increasing dose. Absence of a dose-response trend would tend to argue against causality. Our findings are thus compatible with the presence of a threshold and the absence of risk at low doses, but they might also reflect inadequate statistical power to measure a true risk at environmental exposure levels.

Case-control studies are susceptible to bias, and bias could account for ORs as small as the ones in this study. Because there are no known causes of bone sarcoma other than exposure to ionising radiation and chemotherapy, we have no obvious confounders to adjust for. Radium is found in ground water supplies and not in surface water supplies. Potential biases might thus be ones associated with living in areas supplied by ground water. Most of the major urban centres in Ontario are supplied with surface water, and so exposure to radium is associated with living in smaller cities and in rural areas. Any hypothesis about living in rural areas and increased risk of bone sarcoma would be entirely speculative at this time and we have no exposure data to test any hypothesis other than the one between radium exposure and risk of sarcoma. Our full attention was thus focused on this hypothesis.

The following discussion presumes that Mays' views about the absence of a threshold are plausible, and explores how our findings might fit in with the current body of knowledge about radium risks if we assume lack of statistical power rather than absence of effect as the explanation for the failure for the increased ORs to achieve significance. To make use of the data from both Ontario studies, we undertook pooled analyses. Peto has commented, as follows, about pooled studies. "Data that suggested the hypothesis cannot be used to test it, and such studies should not be pooled formally with subsequent data for the purpose of deciding whether the association is real. Once the hypothesis is regarded as established, however, they should be included for the purpose of quantifying the relationship." 20 We are thus using the data to quantify a relation known to be causal at high doses.

Table 3 shows the results of the data pooling for birthplace exposures. As we had no lifetime exposure data for the subjects of the mortality study, we performed a simulation. We used data on the birthplace and lifetime exposures of the subjects in the registry study to examine the correlation between birthplace exposure and the cumulative activity ratio (fig 1). Most subjects were unexposed at all residences. For subjects who were exposed at the birthplace residence, one can see a correlation between birthplace exposure and cumulative activity ratio. For those subjects, the correlation coefficient between log (birthplace exposure) and $\log$ (activity ratio) is 0.85 ( $\mathrm{P}<$ $0.001)$. There are, however, subjects unexposed at the birthplace residence who were exposed at subsequent residences and who 
Table 6 Risk/Rad and fit to linear dose-response equation for four epidemiological studies

\begin{tabular}{llllll}
\hline Study & Dose (Rad) & $\begin{array}{l}\text { Observed risk } \\
(100000 \\
\text { person-years) }\end{array}$ & $\begin{array}{l}\text { Risk (100 000 } \\
\text { person-years }\end{array}$ & $\begin{array}{l}\text { Risk predicted from } \\
\text { regression equation }\end{array}$ & $\begin{array}{l}\text { Observed } \\
\text { risk/predicted risk }\end{array}$ \\
\hline Dial painters & 6350 & 12200 & 1.92 & 11.494 & 1.06 \\
Dial painters & 3750 & 9466 & 2.52 & 6788 & 1.39 \\
Dial painters & 1751 & 3400 & 1.94 & 3169 & 1.07 \\
Radium-224 & 3100 & 1591 & 0.51 & 5611 & 0.28 \\
Radium-224 & 1345 & 1319 & 0.98 & 2434 & 0.54 \\
Radium-224 & 719 & 263 & 0.37 & 657 & 0.20 \\
Radium-224 & 363 & 286 & 0.79 & 0.64 & 0.34 \\
US PHS & 0.353 & 0.22 & 0.62 & 0.05 & 3.4 \\
Ontario & 0.026 & 0.17 & 6.5 & &
\end{tabular}

thus have a cumulative activity ratio greater than $1 \cdot 0$. To draw inferences about lifetime exposure from measurements of birthplace exposure, we estimated mean values for the proportions of subjects moving from the various birthplace exposure categories to activity ratio categories by drawing 1000 bootstrap samples from the registry subjects. These proportions were then used as transition probabilities to generate cumulative activity ratios from birthplace exposure measurements.

In the simulation, we pooled the 1293 subjects from both studies and drew $527^{\star}$ bootstrap samples. In each bootstrap sample, subjects were assigned a cumulative activity ratio according to their measured birthplace exposure and the transition probabilities computed previously. The ORs for the association between radium and sarcomas were computed for each bootstrap trial, and their distribution in the 527 bootstrap trials was used to compute mean values and $90 \%$ CIs for the ORs.

Table 4 shows the results of the simulations with a dichotomous classification for the lifetime dose. The ORs in the simulation study were higher than in the registry study, attributable to inclusion of subjects from the mortality study, and were significantly increased for all sarcomas and for osteosarcoma. The mean, and geometric mean cumulative activity ratios among exposed subjects were $7.02(95 \% \mathrm{CI}$ : $4 \cdot 1-11 \cdot 4)$ and $3.64(95 \%$ CI: $2 \cdot 94-4 \cdot 48)$ respectively.

Table 5 shows the results of the simulation study for an activity ratio classification of three categories. The ORs were higher than in the registry study and the CIs were narrower, but again the ORs were highest in the middle dose category and there was no trend with dose.

We now compare our results, from the dichotomous dose classification, with those of other studies. Among the people in the registry study, risk of sarcoma was increased by $17 \%$ (38\% in the simulation study) at a (geometric) mean activity ratio of 3.6 (table 4 ). Risk of osteosarcoma was increased by $31 \%$ (44\% in the simulation study). The background incidence of bone sarcoma in the Ontario population is about 1/100 000/year. Excess risk was thus about $0 \cdot 17 / 100000$ /year. The mean age of exposed subjects was 14.2 years. With the metabolic model, ${ }^{7}$ we computed that an activity ratio of $3 \cdot 6$ for 14 year olds corresponds to $2 \cdot 2$ $\times 10^{8}$ excess radium disintegrations in bone,

^The ORs were found to have converged by 527 bootstrap samples. compared with 14 year old subjects with reference level exposure. We adopted the method of Spiess and Mays to compute bone doses: ${ }^{21}$

bone dose $=$

$$
\frac{\begin{array}{c}
\text { number of disintegrations } \\
\text { within bone } \times \\
\text { energy/disintegration }
\end{array}}{\text { skeletal mass }} \times 1.6 \times 10^{-8} \mathrm{Rad} \frac{\mathrm{g}}{\mathrm{MeV}}
$$

where the average energy per disintegration is $10.6 \mathrm{MeV}$. We assumed a bone mass of $4 \mathrm{~kg}$ for a 14 year old child. From this equation, we calculated a mean bone dose of $26 \mathrm{mRad}$ for the Ontario study.

In the US PHS study there were 25 deaths from bone cancer in towns where the mean level of radium in drinking water was $4.7 \mathrm{pCi} / 1$ $(175 \mathrm{mBq} / \mathrm{l})$. In control cities, where the water contained less than $1 \mathrm{pCi} / 1(37 \mathrm{mBq} / \mathrm{l})$, there were 15 deaths, a rate difference of $0.2(95 \%$ CI: -0.17 to $0 \cdot 60) / 100000 /$ year. The exposure difference of about $4 \mathrm{pCi} / 1$ corresponds to a bone dose of about $360 \mathrm{mRad}$ for a 14 year old.

Dose-response data for the dial painter ${ }^{22}$ and medical ${ }^{224} \mathrm{Ra}$ injection ${ }^{21}$ studies were abstracted from the published reports. We used the data from the dial painters and ${ }^{224} \mathrm{Ra}$ studies (we omitted data points with no observed cases) to fit a linear regression line through the origin at zero dose. Figure 2

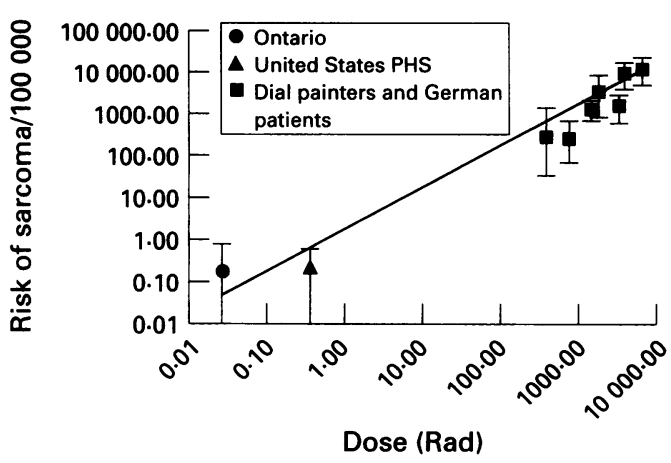

Figure 2 Dose-response relation for bone sarcomas in four populations. The dial painters were occupationally exposed to ${ }^{226} \mathrm{Ra}$ and ${ }^{228} \mathrm{Ra}$. The German patients were injected with ${ }^{224} \mathrm{Ra}$ for the treatment of bone diseases. The US PHS study compared rates of bone sarcoma among residents of midwestern towns where well water contained an average of $4 \cdot 7 \mathrm{pCi} /{ }^{226} \mathrm{Ra}$ with rates among residents of towns with water containing less than $1 \mathrm{pCi}$. The data point for Ontario comes from the subjects with lifetime exposure data. Note that both axes are logarithmically scaled because of the wide range of doses and cancer rates. The line is a linear regression line through the origin from the dial painters and German data. The regression equation is: risk $(1100000 / y)=1.81 \times$ dose $($ Rad $)$. 
shows the regression model and epidemiological data.

For each of the epidemiological studies we computed the risk of sarcoma/Rad (table 6). The mean risk of sarcoma/100 000 personyears/Rad, was $2 \cdot 1$ among the dial painters, was a factor of three lower in the ${ }^{224} \mathrm{Ra}$ and US PHS studies, and a factor of three higher in the Ontario study. Given the uncertainties in dosimetry, is agreement within a factor of three close enough to suggest concordance? Suppose that a childhood tumour other than bone had been the focus of this study. How would the risk factor compare with the risk for dial painters? As ingested radium is concentrated in bone and the radiation is not penetrating, doses are much smaller for other organs. We calculated that, had we found an OR of 1.17 for other childhood cancers, the risk/100 000 person-years/Rad would range from 355 for leukaemia to 6700 for brain cancer, compared with $2 \cdot 1$ for the dial painters and 6.5 for bone sarcoma. The proximity of the bone sarcoma unit risk estimates for the Ontario study and the other epidemiological studies suggests that linear extrapolation to environmental doses might be justified.

We note that the mean dose in the Ontario studies was less than $50 \mathrm{mRad}$, that in the US PHS study was less than 500 mRad, but there were no cases of sarcoma among 440 dial painters with doses less than $1000 \mathrm{Rad}$. We are unable to explain the lack of cases among dial painters at lower doses when we hypothesise the absence of a threshold. Perhaps the fact that the dial painters were exposed as adults, after growth had been completed, is a factor. It has also been suggested that exposure to $\alpha$ particle radiation is more hazardous at lower dose rates. ${ }^{23}$

Food is generally a more important source of radium exposure than is drinking water. The average daily intake in food is about 40 $\mathrm{mBq} /$ day, ${ }^{24}$ although most residents of Ontario ingest less than $10 \mathrm{mBq} /$ day from water. The daily total thus averages $40-50 \mathrm{mBq}$. As food generally comes from remote sources, there is unlikely to be a correlation between radium concentrations in food and water unless local water supplies are used to irrigate fruits and vegetables grown for local consumption. We estimated that risk of bone sarcoma was increased by $17 \%$ at an activity ratio of 3.6 (corresponding to about $13 \mathrm{mBq} / 1$ excess intake). Assuming water consumption of 1 $1 /$ day, $13 \mathrm{mBq}$ is about $30 \%$ of average daily radium ingestion. Thus excess ingestion of $30 \%$ of the average daily intake induces a risk $17 \%$ ( $31 \%$ for osteosarcoma) above background. There are no known causes of bone sarcoma other than exposure to ionising radiation and cytotoxic drugs. ${ }^{14}$ The average daily consumption of radium in food and drink might thus account for most naturally occurring bone sarcomas.
The risks we found at environmental exposure levels were increased, but not always significantly. If we hypothesise that these findings reflect a causal relation, then combining the results of previous epidemiological studies with this one suggests that risk of bone sarcoma is effectively linearly related to dose over five orders of magnitude. This finding might support the common regulatory and radiation protection practice of linearly extrapolating risk observed at high doses to low doses.

This research was supported by a grant from the Ontario Ministry of Health. We acknowledge the assistance of project hydrogeologists Paul Beck and Alex Lye. Jonathan Smith and Peter Yu collected the water samples. The staff of the Peter Yu collected the water samples. The staff of the
Radiation Protection Laboratory of the Ministry of Labour perRadiation Protection Laboratory of the Ministry of Labour per-
formed the radium analyses. Sue Ferrier was the project coordinator.

1 Pershagen G, Akerblom G, Axelson O, et al. Residential radon exposure and lung cancer in Sweden. $N$ Engl $f$ radon exposure and ling

2 Mays C, Rowland RE. Cancer risk from the lifetime intake of $\mathrm{Ra}$ and $\mathrm{U}$ isotopes. Health Phys 1985;48:635-47.

3 Petersen NJ, Samuels LD, Lucas HF, et al. An epidemiologic approach to low-level ${ }^{226} \mathrm{Ra}$ exposure. Public Health Reports 1966;81:805-14.

4 Finkelstein $M$. Radium in drinking water and the risk of death from bone cancer among Ontario youths. Can Med Assoc F 1994;151:565-71.

5 Environmental Protection Agency. Prescribed procedures for measurement of radioactivity in drinking water. Cincinatti: oratory, 1980.

6 Finkelstein MM, Beck P, Yu P. The association between the presence of radium in drinking water supplies and the risk of presence of radium in drinking water supplies and the risk of Ontario Ministry of Labour, April 1993.

7 Leggett RW, Eckerman KF, Williams LR. Strontium-90 in bone: a case study in age-dependent dosimetric modelling. Health Phys 1982;43:307-22.

8 Leggett RW. A generic age-specific biokinetic model for calcium-like elements. Radiation Protection Dosimetry 1992;41:183-98.

9 Health and Welfare Canada. Drinking water consumption in Canada. Ottawa: HWC, 1981.

10 EGRET. Statistical Software. Seattle: Statistics and Epidemiology Research Corporation, 1988.

11 Mooney CZ, Duval RD. Bootstrapping. A nonparametric approach to statistical inference. Newbury Park, CA: Sage Publications, 1993.

12 Moolgavkar SH, Knudson AG. Mutation and cancer: a model for human carcinogenesis. $\mathcal{F}$ Natl Cancer Inst 1981; 66:1037-52

13 Schottenfeld D, Fraumeni JF. Cancer epidemiology and prevention. Philadelphia: WB Saunders, 1982.

14 Tucker MA, D'Angio GJ, et al. Bone sarcomas linked to radiotherapy and chemotherapy in children. $N$ Engl $f$ Med 1987;317:588-93

15 Rowland RE, Stehney AF, Lucas HF. Dose-response relationships for radium-induced bone sarcomas. Health Phys 1983;44(suppl 1):15-31.

16 Mays CW, Spiess $H$. Bone sarcomas in patients given radium-224. In: Boice JB, Fraumeni JF, eds. Radiation carcinogenesis: epidemiology and biological significance. New Yarcinogenesis: epidemiolog

17 Fried SH, Dryja TP, Weinberg RA. Oncogenes and tumorsuppressing genes. N Engl fMed 1988;318:618-22.

18 Raabe OG, Book SA, Parks NJ. Lifetime bone cancer doseresponse relationships in beagles and people from skeleta burdens of ${ }^{226} \mathrm{Ra}$ and ${ }^{90} \mathrm{Sr}$. Health Phys 1983;44(suppl 1) 33-48.

19 Mays CW. Alpha particle induced cancer in humans Health Phys 1988;55:637-52.

20 Peto J. Meta-analysis of epidemiological studies. In: Vainio H, Magee P, McGregor D, McMichael AJ, eds. Mechanisms of carcinogenesis in risk identification. Lyon: International agency for Research on Cancer, 1992. (IARC Sci Publ No 116.)

21 Spiess $\mathrm{H}$, Mays CW. Bone cancers induced by ${ }^{224} \mathrm{Ra}$ in children and adults. Health Phys 1970;19:713-29.

22 Rowland RE, Stehney AF, Lucas HF. Dose-response relationships for female radium dial painters. Radiation tionships for female radiur
Research 1978;76:368-83.

23 Lubin JH, Boice JD, Edling C, et al. Lung cancer in radonexposed miners and estimation of risk from indoor expoexposed miners and estimation of risk from
sure. $\mathcal{F}$ Natl Cancer Inst 1995;87:817-27.

24 United Nations Scientific Committee on the Effects of Atomic Radiation. Effects of atomic radiation. New York: UNSC, 1977. 